\title{
Research and Application of the Electromotion Elevator for Mechanized Workover Progress
}

\author{
Zhang Hui $^{\mathrm{a}}$, Song Huihuii ${ }^{\mathrm{b}}$, Su Qiuhan ${ }^{\mathrm{c}}$, Tang Qianwen ${ }^{\mathrm{d}}$, Fu Zeng ${ }^{\mathrm{e}}$ \\ Research Institute of Oil Production Technology, Shengli Oilfield, Sinopec, China \\ azhanghuigoal@163.com, bsonghuihui.slyt@sinopec.com, ${ }^{\text {c}}$ cissyandmaggie@163.com, ${ }^{\mathrm{d}}$ tqw.7@16 \\ 3.com, ${ }^{\mathrm{e}}$ fuzeng.slyt@sinopec.com
}

Keywords: workover; elevator; FEM;

\begin{abstract}
The elevator being used in field application causes several problems such as low level of mechanization and high intensity of labor. Therefore, electromotion elevator is developed and tested in this paper, which works with mechanized workover equipments. On the base of traditional elevator, the safety pin for the rings is driven by a spring and its own gravity, while the door of the elevator, with self-locking function, is driven by a DC motor which is remotely controlled. Through the field test and application, the electromotion elevator shows desirable safety, reliability and continuous working ability, which satisfy the requirement of workover operation.
\end{abstract}

\section{Introduction}

Elevator is one of the commonly used tools for lifting and lowering oilfield tubular out of, or into an oil, gas or geothermal well. In hoisting a joint of tubular, the elevators are latched onto the pipe below the tool joint which prevents the pipe from slipping through the elevators ${ }^{[1-2]}$.

In the process of workover operation, the movement of the elevator, the opening and closing of the elevator door and the safety pin were manually finished, which leaded to high labor intensity, complex procedure and some security risks. As the oil and gas exploitation in some oil field comes to the late stage, workover operation frequency increased greatly, and the disadvantages of traditional elevators have become increasingly prominent ${ }^{[3-4]}$.

The elevators driven by hydraulic power have been produced by the famous petroleum equipment manufacturers such as National Oilwell Varco (BX series) and Blohmand Voss Repair $\mathrm{GmbH}^{[5]}$. Typically the hydraulic elevators were hinged to the hook with a hydraulic pipeline and the workers operated the elevator in the distance. However, because of the existence of hydraulic pipeline, the elevator could not be taken turns and the working radius was quite limited. In additional, the hydraulic elevators were usually of big size and weight, which was more suitable for drilling and completion but the workover process. In this paper, an electromotion elevator is designed, optimized and tested in field application.

\section{Structure and Working Principle}

Using a traditional elevator body, the electromotion elevator has four newly designed parts, named motor driven door, safety pin, and waterproof cover, respectively.

Motor driven door. The motor driven door comprises a DC motor, a worm-gear reducer, transmission gears, a door with gear teeth and battery, as shown in Fig. 1. The door could be rotated by the motor to close or unclose the hatch of the elevator body. There are three advantages in using a worm-gear shape reducer: transmitting the rotary motion from the motor to the door, increasing the driving torque and locking the door to prevent the tube from slipping through the elevator taking advantage of the function of anti-directional self-locking. 


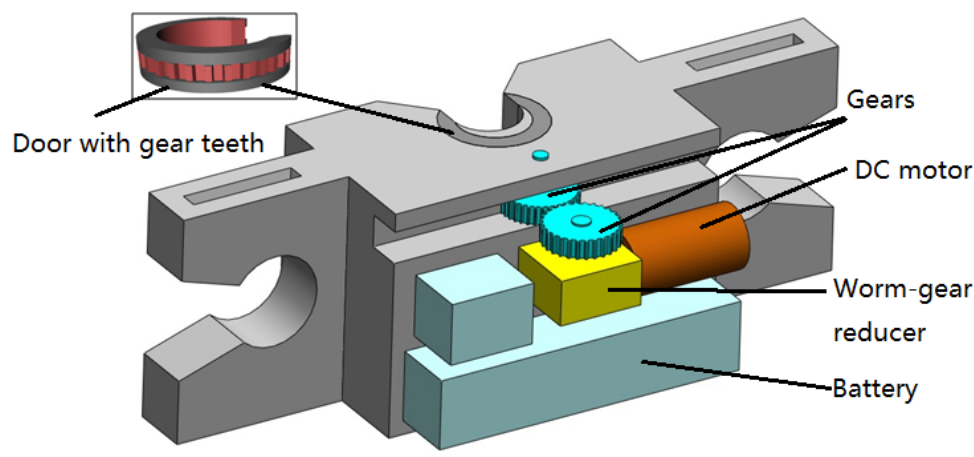

Fig. 1 Schematic diagram of motor driven door

The opening and closing of the door depends on the forward and reverse rotation of the DC motor and the motor is controlled by the electrical control system. The electrical control system comprises electromagnetic relay switches and distance controller. The work radius of the controller is more than 30 meters.

Safety pin. There is one safety pin hole in each hanger arm, and the hole is rectangular and symmetrical to the central axis. The safety pins are of " $U$ " shape and are installed in the holes together with a compression spring. One end of the spring is fixed to the elevator body and the other end is fixed to the pin.

When the elevator is put on the wellhead platform, the end A of the safety pin will get in touch with the plane and the spring will be compressed by the gravity of the elevator body, as a result the end $\mathrm{B}$ of the pin will retract into the hanger arm to make room for the insertion and removal of the elevator bail.

Once the elevator is hoisted by the elevator bail, the end A of the pin will be pulled out under the action of the elastic force of the spring, meanwhile the end $B$ of the pin approach the bottom of the gap of the hanger arm. Then the bails are entrapped and cannot fall off the elevator.

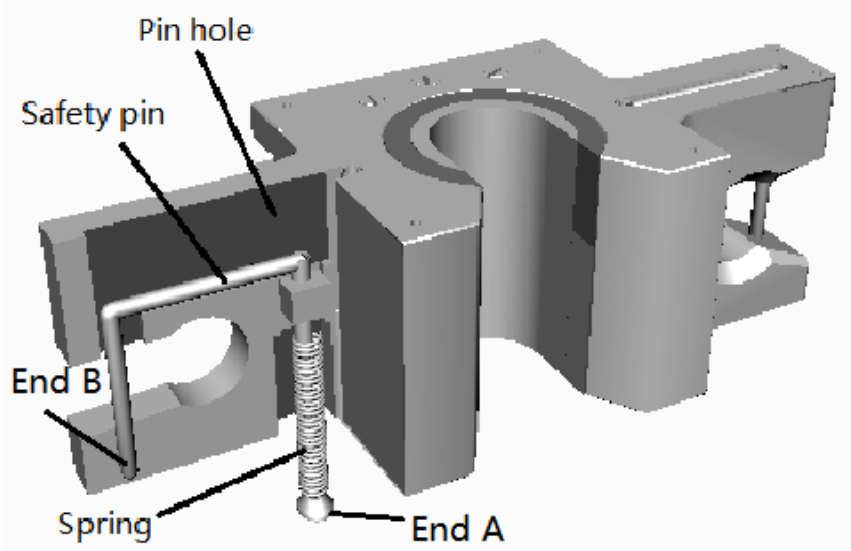

Fig. 2 Schematic diagram of safety pin

Waterproof cover. The well fluid generated by overflow an extrusion contains water and oil which may do great harm, such as corrosion and short circuit. By the field test, the water entering into the electric control system may by splashing to the elevator directly or through the opening of the elevator crescent. So the waterproofing ability of all the motor and other electrical components must reach level IP-4 to prevent the water resulting in the short circuit faults.

A lot of $\mathrm{Cl}^{-}, \mathrm{S}^{2-}$ and etc. ions due to the high salinity underground, so the above electrical components can be corroded by the well fluid. Therefore the electrical system of the crescent should be sealed further. The sealing device is showed in the Fig. 3. In which the motor and battery are placed in a whole metal shell, and the shell and the rear cover form the complete sealing region $\mathrm{A}$ by the rubber strip to prevent the water splashing into the electrical system. 


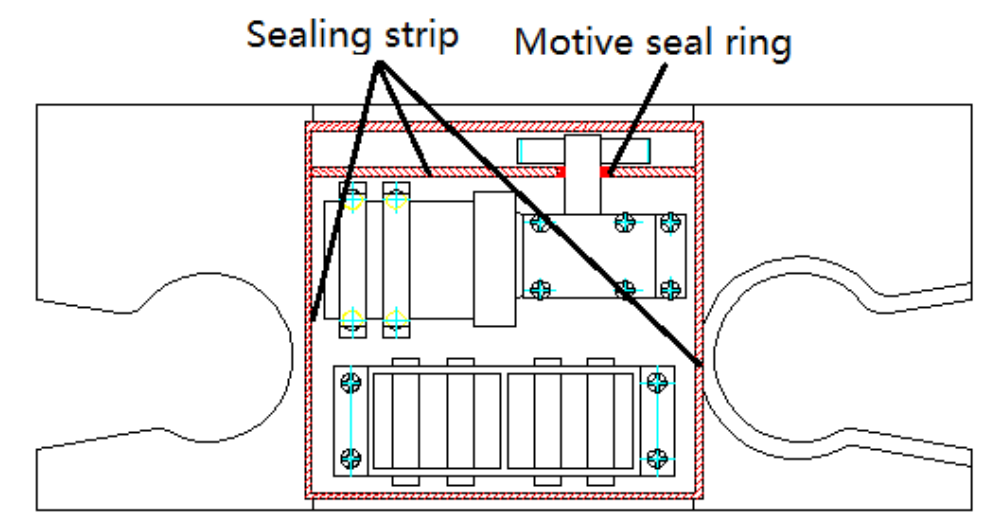

Fig. 3 Sealing schematic diagram of the elevator

The transmission shaft driven by the reducer passes through the upper end cover of the sealing region $\mathrm{A}$ to the region $\mathrm{B}$. The packing sealing is used to seal the transmission shaft and the region $\mathrm{A}$ and $\mathrm{B}$ to avoid the water inflowing from the elevator crescent entering into the region $\mathrm{A}$. The bottom of region $\mathrm{B}$ inclines a certain angle and has a diversion trench. The outflow holes are designed at the both ends to eliminate the well fluid in time. The transmission gears contact with little well fluid unavoidably, so the stainless steel gears are selected.

\section{Stress Analysis}

The elevator is one of the main bearing tools during workover operation. The electric elevator designed in the paper contains many holes, the bearing ability of which must be influenced. Therefore the stress distribution was calculated by FEM software.

The common 40t elevator was chosen to simulate. The rated load was 40 ton, and the material was 40Cr. The properties of the material are shown in Table 1.

Table 1 Properties of elevator material

\begin{tabular}{ccc}
\hline Density & Elasticity modulus & Poisson ratio \\
\hline $7.9 \mathrm{~kg} / \mathrm{m} 3$ & $206 \mathrm{GPa}$ & 0.28
\end{tabular}

The stress nephogram of the elevator body are shown in Fig 4. Obviously, the maximum Mises stress in the elevator with and without pin holes are 228.0 and 235.3 MPa respectively. The result illustrate that the holes in the elevator body can decrease the maximum stress and improve the safety factor. The yield strength of $40 \mathrm{Cr}$ is $780 \mathrm{MP}$, the safety coefficient of elevator is:

$$
n_{\mathrm{s}}=\frac{\sigma_{\mathrm{s}}}{\sigma_{\text {Rated }}}=\frac{780 \mathrm{MPa}}{228 \mathrm{MPa}}=3.42
$$

According to the standard (SY/T5035-2004), the safety coefficient of elevators below 150 tons is 3.00 , thus the elevator can meet the design requirement.

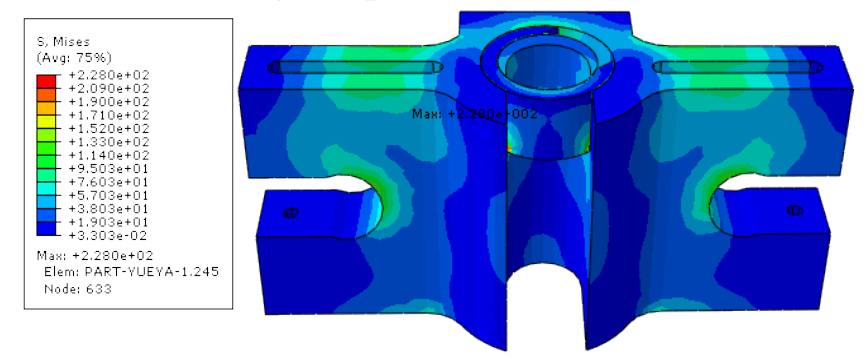

(a) Elevator with holes 


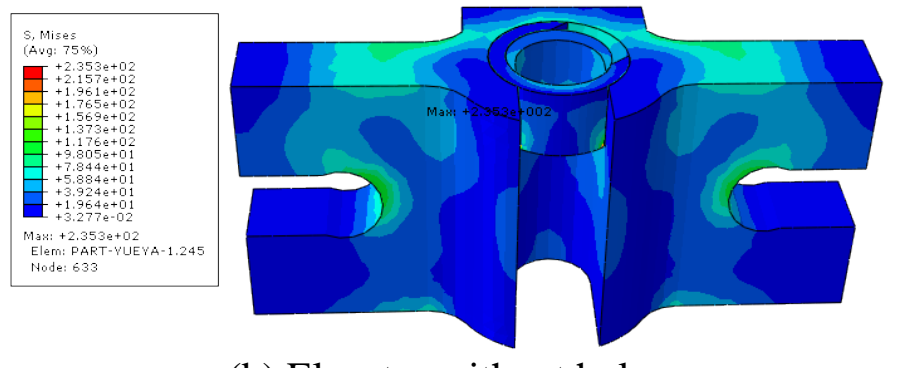

(b) Elevator without holes

Fig. 4 Nephogram of the elevator with load of 40 tons

\section{Conclusion}

(1) The door and the safety pin of electromotion elevator can be opened and closed automatically. Compared to traditional hydraulic elevators, the elevator no longer fixed to the hook and could be transmitted among different workstations because of the omission of hydraulic pipeline.

(2) The opening and closing of the safety pin was controlled by the spring and the gravity of the elevator body employing no power mechanism, which made the operation easier. The worm-gear reducer could lock the door to prevent it form unpredictable opening.

(3) The hole for safety pin could disperse the stress and decrease the maximum stress of the elevator which improved the safety coefficient of the elevator.

(4) According to the site test, the electromotion elevator could meet the work conditions such as high temperature, overflow and extrusion and the elevator could be used for more than 500 times once fully charged.

\section{Acknowledgement}

The work is supported by “Sinopec Science and Technology Project (312053)”.

\section{References}

[1] Zhang Baozeng, Wang Ruihe: China Petroleum Machinery, Vol. 36(2007), p. 22-25

[2] Chang Yulian, Wei Kai, Gao Sheng: Vaue Enineering, Vol. 12(2013), p. 48-491

[3] Zhang Baozeng, Wang Ruihe: China Petroleum Machinery, Vol. 34(2006), p. 49-51

[4] Chang Yulian, Zhan Guanjie, Gao Sheng: China Petroleum Machinery, Vol. 36(2008), p. 188-19

[5] He Hong, Yan Yonghong, Wang Degui: China Petroleum Machinery, Vol. 40(2012), p. 29-37 